Supporting Information

\title{
Synthesis and Charge Storage Properties of Hierarchical Niobium Pentoxide/Carbon/Niobium Carbide (MXene) Hybrid Materials
}

Chuanfang (John) Zhang, Majid Beidaghi, Michael Naguib, Maria R. Lukatskaya, Meng-Qiang Zhao, Boris Dyatkin, Kevin M. Cook, Seon Joon Kim, Brandon Eng, Xu Xiao, Donghui Long,* Wenming Qiao, Bruce Dunn,* Yury Gogotsi* 

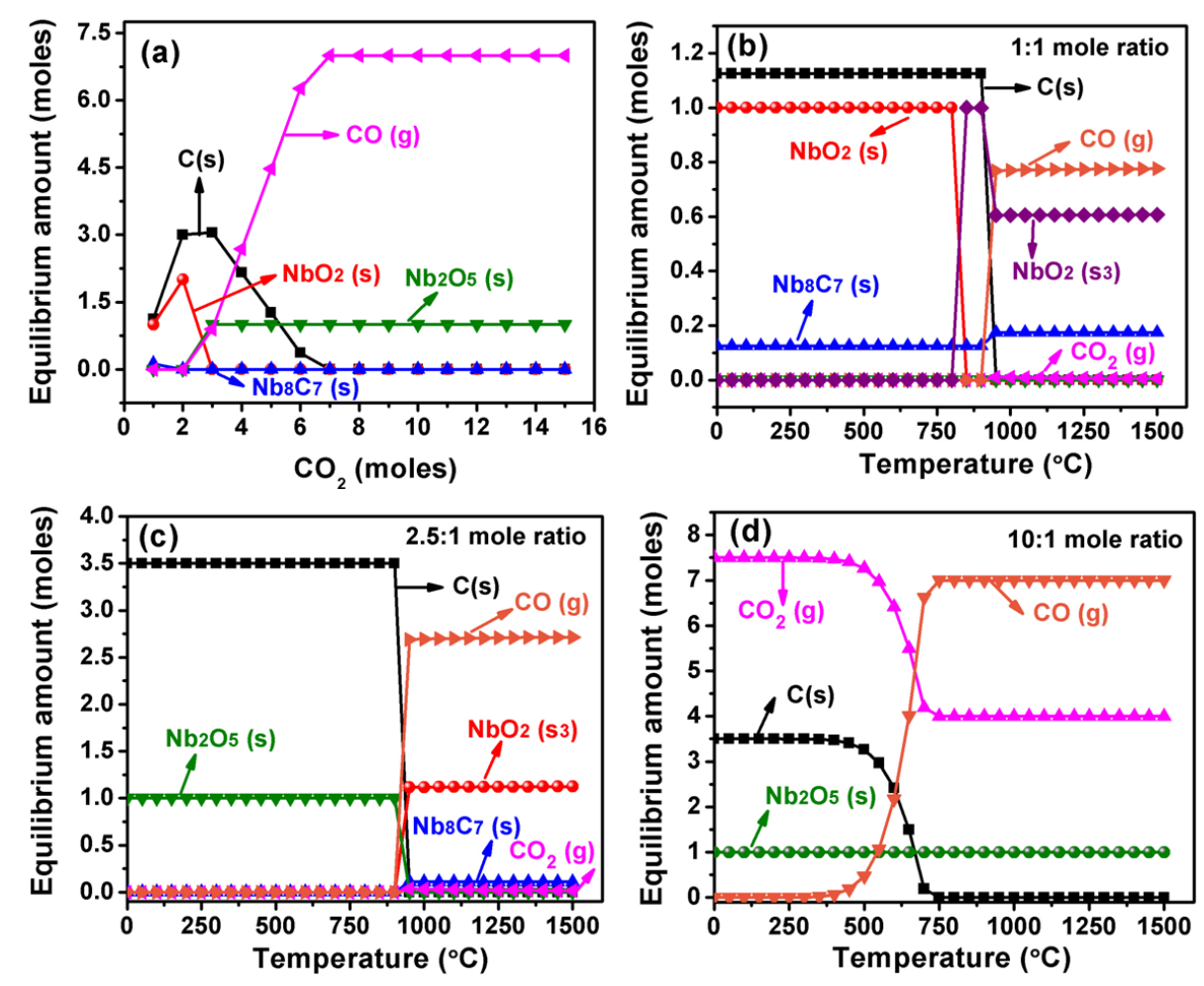

Figure S1. a) Thermodynamics calculations for the closed system of $\mathrm{Nb}_{2} \mathrm{CT}_{\mathrm{x}}-\mathrm{CO}_{2}$ at $1 \mathrm{~atm}, 850{ }^{\circ} \mathrm{C}$ as a function of number of $\mathrm{CO}_{2}$ moles; $\mathrm{CO}_{2}$ to $\mathrm{Nb}_{2} \mathrm{CT}_{\mathrm{x}}$ molar ratio of b) 1.0:1.0; c) 2.5:1.0 and d) $10: 1.0$

The effect of $\mathrm{CO}_{2}$ feed (moles, $\mathrm{x}$ ) on the composition of the hybrid material is presented in Figure S1a assuming the oxidation at a constant pressure and temperature $\left(1 \mathrm{~atm}, 800^{\circ} \mathrm{C}\right)$. When the $\mathrm{CO}_{2}$ feed is low $(1<\mathrm{x}<2)$, thermodynamic calculations predict the oxidation of $\mathrm{Nb}_{2} \mathrm{CT}_{\mathrm{x}}$ into carbon and $\mathrm{NbO}_{2}$. Increasing the $\mathrm{CO}_{2}$ feed $(3<\mathrm{x}<7)$ would decrease the carbon content and convert the $\mathrm{NbO}_{2}$ to $\mathrm{Nb}_{2} \mathrm{O}_{5}$ gradually. Excessive $\mathrm{CO}_{2}$ feed $(\mathrm{x}>7)$ would result in complete oxidation of carbon (Figure S1a). These results suggest the $\mathrm{CO}_{2}$ feed in the reaction system is crucial in tuning the resulting composition. Figures S1b-d present the equilibrium compositions as a function of oxidation temperature and under different mole ratios of $\mathrm{CO}_{2}$ to $\mathrm{Nb}_{2} \mathrm{CT}_{\mathrm{x}}$. When the mole ratio is equal to $1: 1$, the product contains $\mathrm{NbO}_{2}$ and $\mathrm{Nb}_{8} \mathrm{C}_{7}$, rather than $\mathrm{Nb}_{2} \mathrm{O}_{5}$, suggesting that the amount of $\mathrm{CO}_{2}$ is insufficient (Figure $\mathrm{S} 1 \mathrm{~b}$ ). When the mole ratio increases to $2.5: 1$ or $10: 1, \mathrm{Nb}_{2} \mathrm{O}_{5}$ and carbon become the main species within the preferred temperature range of $<875^{\circ} \mathrm{C}$ (Figure S1c) and $\angle 700{ }^{\circ} \mathrm{C}$ (Figure S1d), respectively. These thermodynamic calculations provided guidance, which enabled us to select the $\mathrm{CO}_{2}$ feed and oxidation temperature in order to reach the desired composition of the hybrid material. 

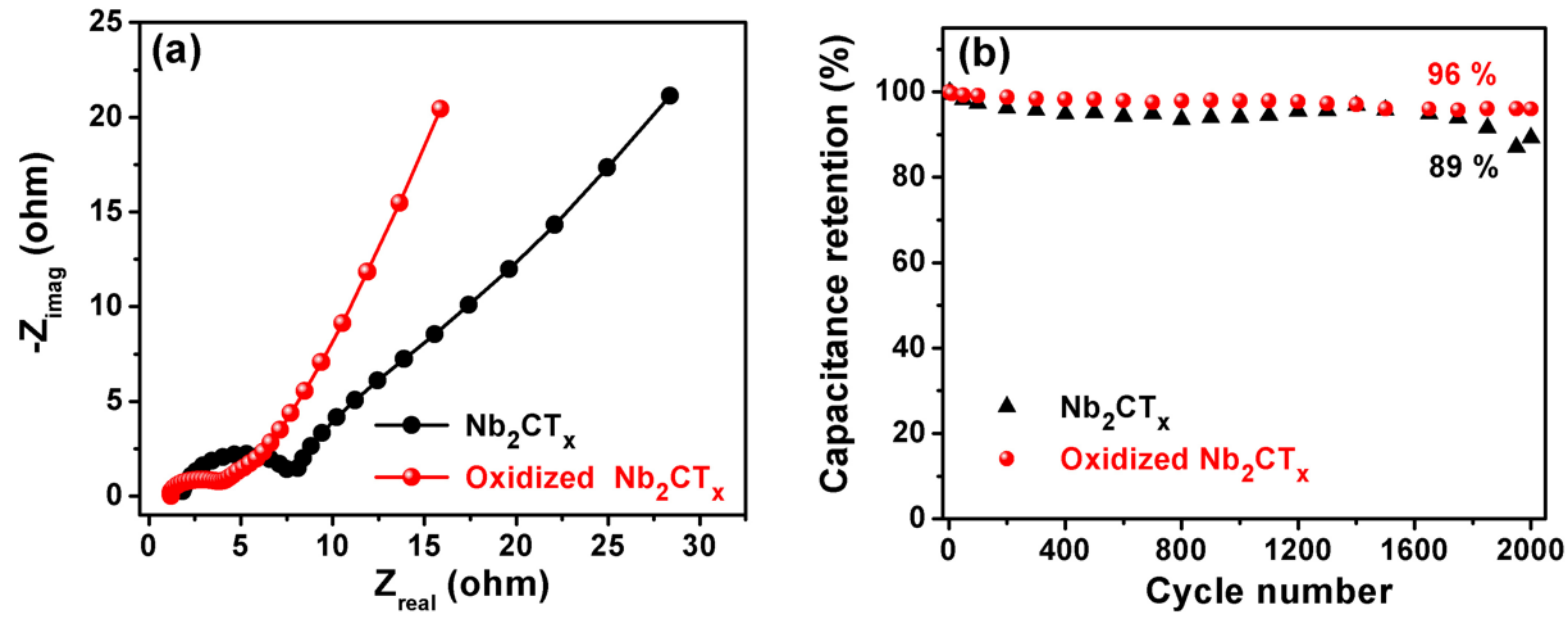

Figure S2. a) Nyquist plot and b) cycle life comparison of $\mathrm{Nb}_{2} \mathrm{CT}_{\mathrm{x}}$ before and after oxidation at $800{ }^{\circ} \mathrm{C}$ for $1 \mathrm{~h}$ at $150 \mathrm{sccm}\left(\mathrm{CO}_{2}\right.$ flow rate).

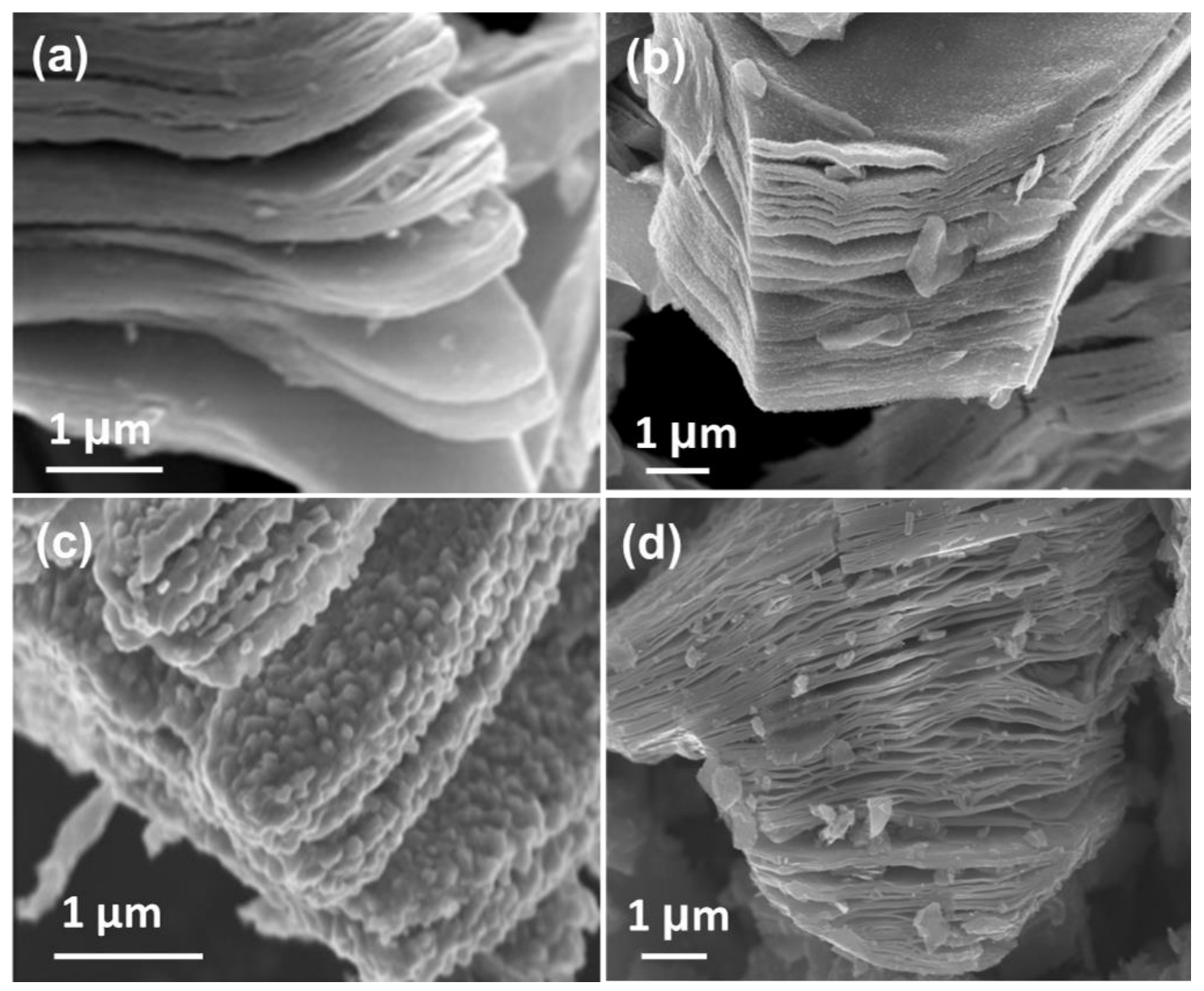

Figure $\mathrm{S3}$ a) SEM images of $\mathrm{Nb}_{2} \mathrm{CT}_{\mathrm{x}}$ powders treated at a) $600{ }^{\circ} \mathrm{C}$; b) $750{ }^{\circ} \mathrm{C}$, c) $850{ }^{\circ} \mathrm{C}$ in $\mathrm{CO}_{2}$ and d) $850{ }^{\circ} \mathrm{C}$ in Ar. The duration for the heat treatment was fixed to $1 \mathrm{~h}$ with $\mathrm{CO}_{2}$ (or Ar) flow rate of $150 \mathrm{sccm}$. 


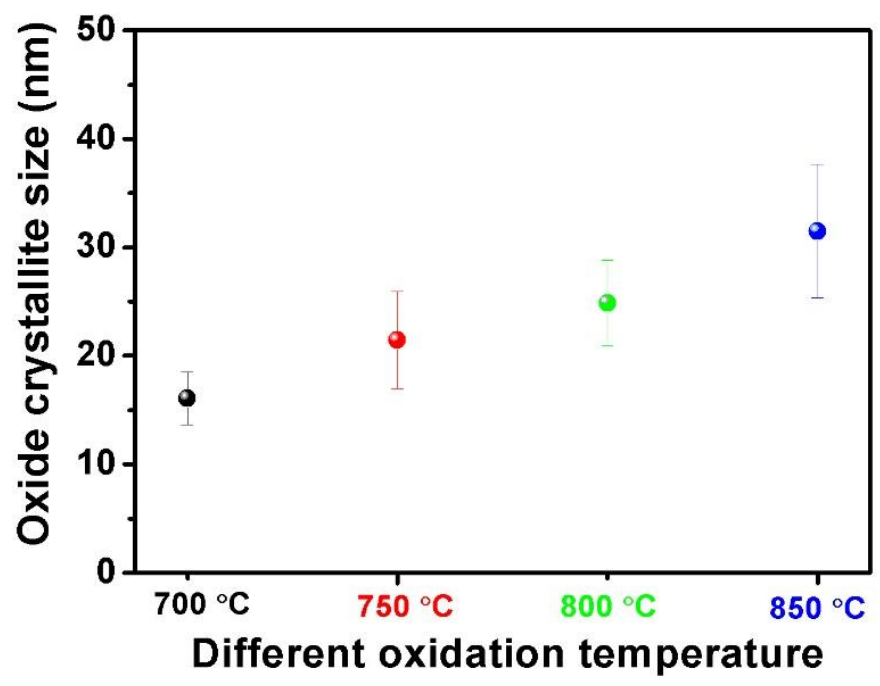

Figure S4. $\mathrm{Nb}_{2} \mathrm{O}_{5}$ crystallite size in $\mathrm{Nb}_{2} \mathrm{CT}_{\mathrm{x}}$ oxidized at different tempeartures. The duration for the heat treatment was fixed to $1 \mathrm{~h}$ with $\mathrm{CO}_{2}$ flow rate of $150 \mathrm{sccm}$.

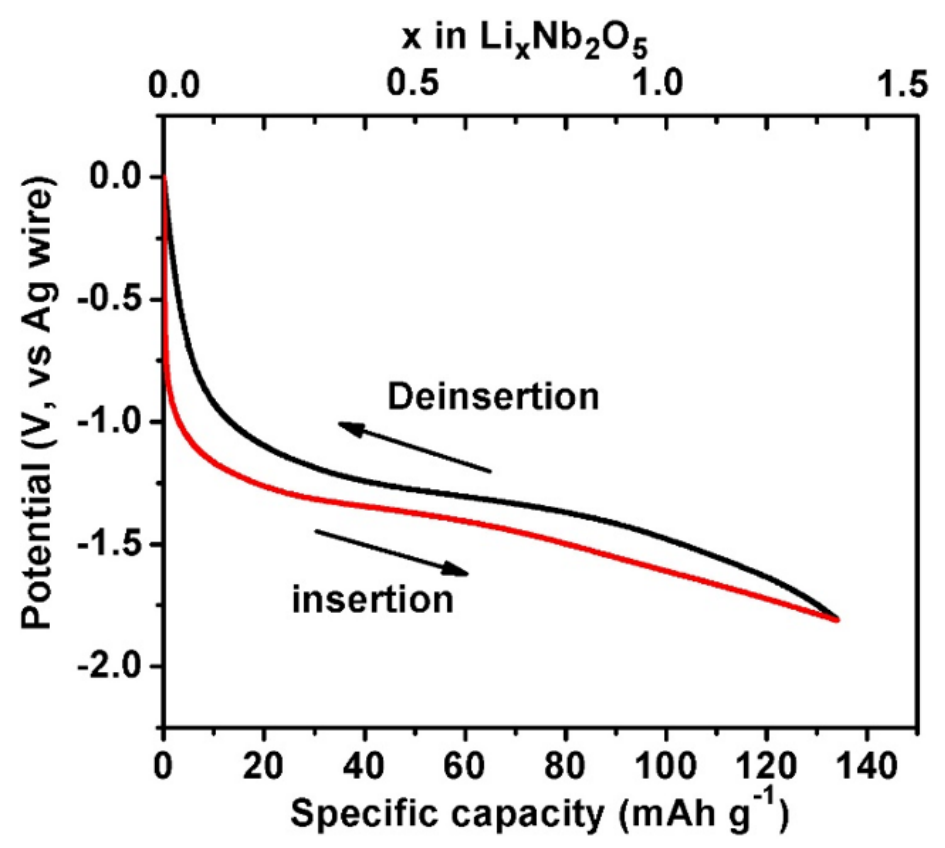

Figure S5. Galvanostatic charge-discharge profile of oxidized $\mathrm{Nb}_{2} \mathrm{CT}_{\mathrm{x}}\left(850^{\circ} \mathrm{C}, 1 \mathrm{~h}, 150 \mathrm{sccm}\right)$ at 0.1 $\mathrm{Ag}^{-1}$. 

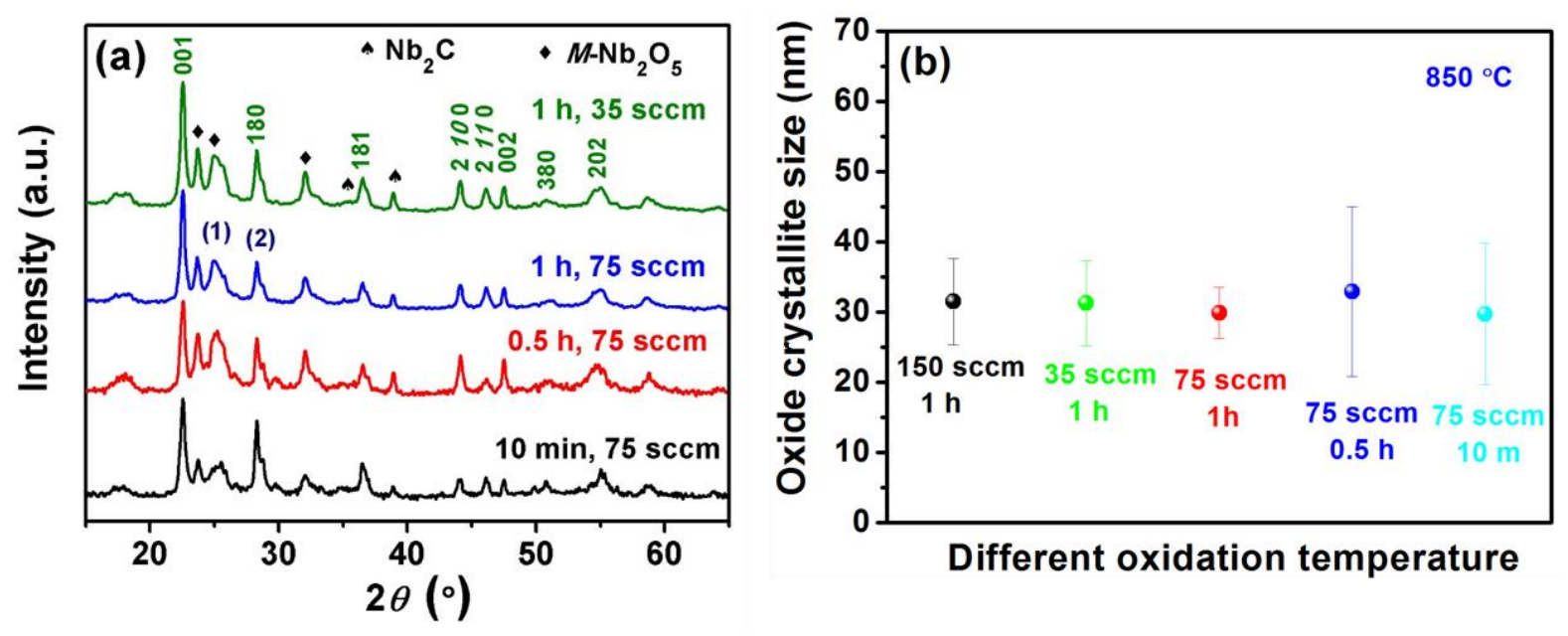

Figure S6. a) XRD patterns and b) $\mathrm{Nb}_{2} \mathrm{O}_{5}$ crystallite size of $\mathrm{Nb}_{2} \mathrm{CT}_{\mathrm{x}}$ oxidized under various conditions. The temperature for the heat treatment was fixed to $850{ }^{\circ} \mathrm{C}$
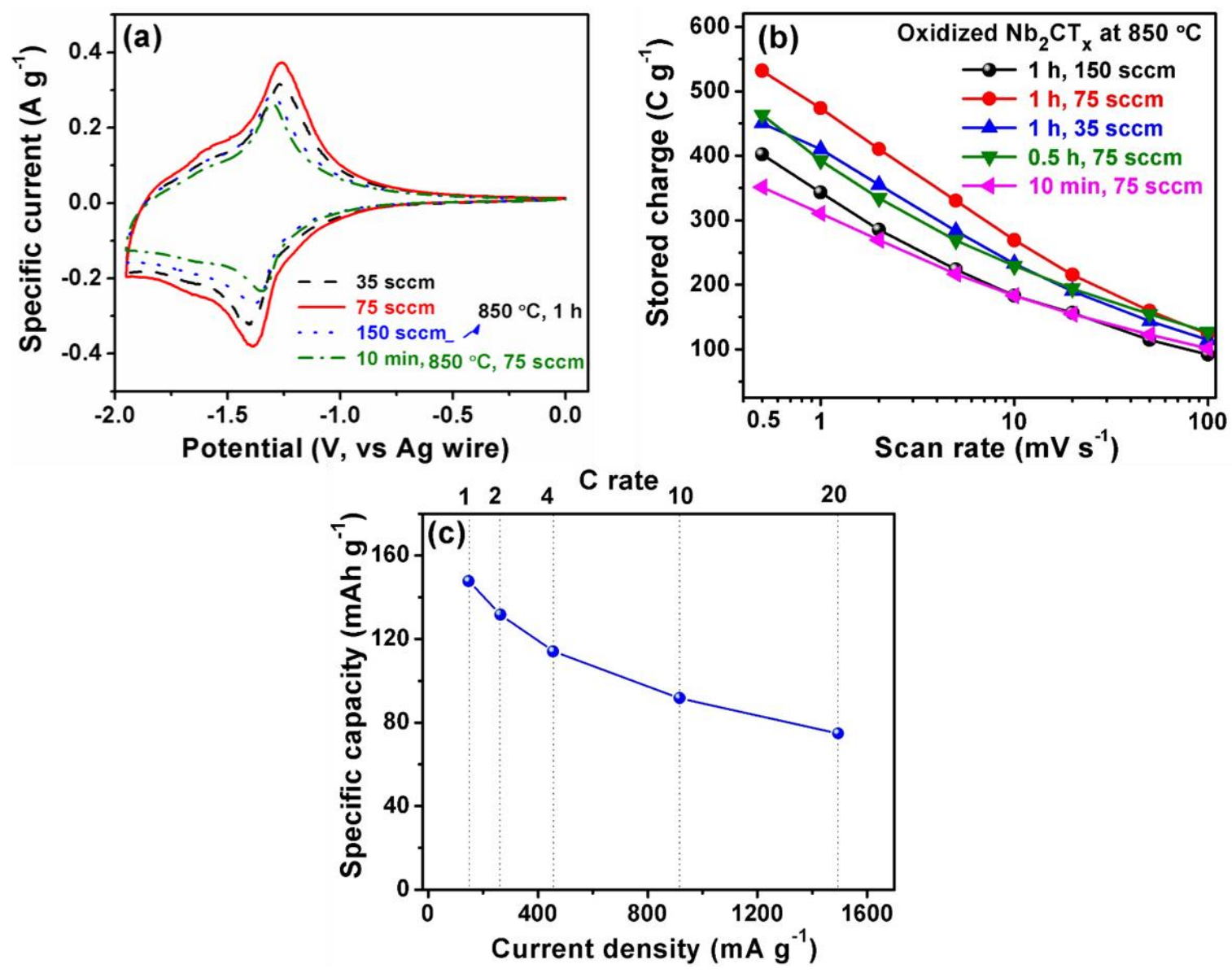

Figure S7. a) CV curves at $0.5 \mathrm{mV} / \mathrm{s}$ and b) rate performances of different oxidized $\mathrm{Nb}_{2} \mathrm{CT}_{\mathrm{x}}$; c) specific capacity of oxidized $\mathrm{Nb}_{2} \mathrm{CT}_{\mathrm{x}}\left(850{ }^{\circ} \mathrm{C}\right.$ for $1 \mathrm{~h}$ at $\left.75 \mathrm{sccm}\right)$ at different current densities and C-rates. 